\section{Differing approaches to genetics}

SincF a knowledge of genetics is now considered an important ingredient of many undergraduate courses, as widely disparate as molecular biology and sociology, very different approaches to the subject are to be expected. This is reflected in several undergraduate texts which have appcared in the past year.

M. I. Lerner and W. J. Libby's Heredity, Evolution and Society (Freeman: San Francisco, second edition, $\$ 13.95 ; £ 8.80$ ) is concerned more with the social consequences of genetics, although it would be unfair to suggest that the authors have neglected the scientific basis of the subject. The emphasis throughout is on the relationship between genetics and evolution. particularly human evolution. Yet though largely, but not exclusively; concerned with human genetics the text is not over-burdened with obscure clinical references which often reduce the appeal of such texts to science students. The standard arrangement of most student textbooks of genetics is not followed. For example, chromosome structure and function are not dealt with as such but are included in chapters on gene interaction, sex and mutation. An attractive feature of the book is the use of inserts, called 'boxes', in which are segregated most of the descriptive, biographical and tabular material. This is a clearly written text which is eminently readable.

Many biologists are daunted by genetics because of the emphasis on statistics. D. T. Suzuki and A. J. F. Griffiths recognise this problem, and their book. An Introduction to Genetic Analysis (Freeman: San Francisco, \$13.95) “. . . attempts to teach the reader how to do genetics". This is therefore not strictly a textbook, for it is not just concerned with concepts but is more a guide as to how to analyse genetic data. The approach is essentially quantitative. although a level of mathematical sophistication no greater than simple algebra is required. It is clearly meant to be a didactic text, extensive use being made of a questionand-answer format, problem-solving exercises (a separate book of answers is available). and the dispersal within the text of so-called "messages" which summarise important information. Therc are also sequences of diagrams illustrating mitosis, meiosis. DNA replication and translation which can be animated by letting the pages flip over. This latter device is not really very satisfactory and seems out of place in a University text. Quantitative problems in all aspects of genetics are considercd including Mendelian segrega- tion, linear and circular linkage analysis (but not lod score methods), cytogenetic mechanisms and mutation. There is also a chapter on population genetics. Perhaps it is in this latter field that mathematical analysis has been most important, yet this is given relatively little attention. The book is wide ranging in the material chosen to illustrate problems in genetic analysis, but it is difficult to see how it will survive competition with more conventional texts.

N. V. Rothwell's book Understanding Genetics (Williams and Wilkins: Baltimore, \$14.95), is perhaps the most conventional of these texts. It deals in the usual manner with the mechanisms of gene action, cytogenetics, various aspects of biochemical genetics and population genetics. The molecular basis of inheritance is dealt with very well indeed but rather oddly is relegated to the latter half of the book. This text provides a straight-forward account of genetic mechanisms illustrated by examples from widely related organisms. The illustrations are simple straight-forward line drawings which are very attractively presented. Each chapter concludes with some well chosen references, although very few of these are more recent than 1970. Apart from the chapter on probability there are no student exercises.

W. Hexter and H. T. Jost's The Science of Genetics (Prentice-Hall: Englewood Cliffs, New Jersey, £11.90: $\$ 18.95$ ) is also an introductory text designed primarily for biology students. but here the authors have tended to

\section{Abundant facts of immunology}

Basic and Clinical Immunology. Edited by' H. H. Fudenberg, D. P. Stites, J. L. Caldwell and J. V. Wells. Pp. 653. (I.ange Medical Publications: Los Altos, California, 1976.) \$12.50.

THIS large book is good value for money. Its intent is to act as a source from which the enquiring mind may obtain the abundant facts of immunology. There are impurities in this spring of knowledge some of which should disappear in the promised biennial revisions. The editors solicit our specific advice on this point.

The tone of the book is authoritarian and the referencing is inadequate to check the origins of many of the statements made. This may be in line with the current teaching of medical students but it is irritating for the more curious reader. The indexing is capricious, which is probably inevitable in a book use a historical approach in order to emphasise the reasoning which initiated critical studies and lead to important conclusions. The hope is that the book will have a two-fold purpose: ". . to introduce the student to the essential facts of genetics and to introduce the student to the methods of science". In general the authors have been successful. Again. illustrative examples are widely chosen from both the plant and animal kingdoms. Of student texts which deal primarily with the science of genetics, this is perhaps the most readable and exciting, probably because of the emphasis on the evolution of concepts and ideas. It also becomes quite clear where there are still some major gaps in our knowledge and understanding. as in the case of chromosome structure. The book is enhanced by simple straight-forward line drawings and with references to key papers. Each chapter concludes with a number of exercises but no answers are provided.

These four books therefore reflect very different approaches to genetics. For those whose main interest lies in human problems and the social consequences of genetics, Lerner and I..ibby's hook can be unreservedly recommended. For those who want a more standard undergraduate text of general genetics, Hexter and Jost's book is perhaps the best.

Alan E. H. Emery

Alan E. H. Emery is Professor of Human Genetics at the University of Edinburgh, UK.

with forty chapters written by many different people. The line drawings are first class but the reproductions of photographs are in the main of indifferent quality.

The first half of the book deals with the basic aspects of immunology starting with a delightful chapter by Grabar on the historical background. The short chronology on important achievements in immunology, which terminates this particular piece, ends at 1959 at a time when many might think immunology was just beginning to gather steam.

The second half of the book starts with a summary of the methods in common use in immunodiagnosis and concludes with a series of chapters on clinical immunology.

The book is fascinating and reminiscent of Florey's texts on general pathology. My reservations simply concern the difficulty of teaching rapidly changing subjects without perpetuating too many errors.

A. J. S. Davies

A. J. S. Davies is Professor of Immunobiology in the University of London, working at the Chester Beaty Research Institute, London, UK. 